\title{
On the Measurement of Social Progress and Wellbeing: Some Further Thoughts
}

\author{
Jean-Paul Fitoussi \\ Institut d'Etudes Politiques de Paris \\ Joseph E. Stiglitz \\ Columbia University
}

\begin{abstract}
Since 2008, the world has experienced several dramatic events: the financial crisis of 2007-08, the earthquake in Japan, the sovereign debt crisis and the revolutions in the Arab world. All of these developments have called into question not just our current policies, but also the measurement systems on which we base their configuration. What we measure affects what we do. Increasingly, there is a demand to go beyond measures of market activity (GDP) and towards measures of wellbeing. Reductions in wellbeing (following deteriorations in people's physical and psychological health, community life or employment status, or in the provision of environmental goods) that are accepted in the name of maximization of material wealth results in totally misguided policies. This article surveys some recent and clear instances in which our measurements have gone wrong, and suggests revisions that may translate into better informed and more sustainable policies.
\end{abstract}

\section{The shortcomings of our metrics}

Since 2008, the world has experienced several dramatic events: the financial crisis of 2007-08, the earthquake in Japan, the sovereign debt crisis and the revolutions in the Arab world. All of these developments have called into question not just our current policies, but also the measurement systems on which we base their configuration.

The 'financial' crisis revealed that we were not doing as well as the available metrics led us to believe. The ways in which we were trying to grow economically turned out to be fragile, or otherwise unsustainable, with output measures having been exaggerated by bubble prices in real estate, as well as by fictional profits in the financial sector. In some countries (such as the US), GDP has now returned to precrisis level, but that does not in any way account for a palpable diminution in the general sense of wellbeing of people. Almost one out of six Americans would like a full-time job, the availability of which is limited; others face high anxiety about the risk of losing their current employment and homes; others still are threatened with significant cutbacks in basic public expenditure programmes. GDP may be looking alright, but the loss in wellbeing is enormous.

The aftermath of the earthquake in Japan can be seen as a metaphor of our measurement problems. Our very thinking seems strangely out of focus. For instance, it was suggested that, while in the short run Japan's GDP may have gone down, in the long run it would have risen as a result of reconstruction efforts. Some have also suggested that the increased sense of danger and anxiety caused by the calamity might have significant health effects on a large section of the population, the alleviation of which through drugs and treatments may increase GDP. These claims are strange but may have a grain of truth in them. What no one would claim, however, is that Japan is actually better off after the earthquake. It would require such a huge increase in GDP to compensate for the destruction of all the kinds of capital that the event caused, and to offset the increased anxieties that so many people face in the country today, that there is virtually no way Japan (or any country) could ever end up being better off as a result of such a catastrophe. But our metrics are not capable of measuring the value of the lost assets. The mechanical nature of our economic models tells us nothing about the immaterial consequences of the irreversible losses suffered by the Japanese people. In the aftermath of the disaster, we also realize that the measurements we were making before the disaster were not accurate either. GDP may have been higher then because of greater cost savings made possible by the use of nuclear energy as opposed to, say, renewables. Disposal policies for spent nuclear 
material that exposed the entire country to great risks, which are all too evident now, may also have contributed to an apparently higher GDP. The Japanese case underlines the three major shortcomings of our metrics: the measurement of the 'economic product', the measurement of wellbeing and the measurement of sustainability.

Another well-documented fact is intracountry increase in inequality, which has characterized at least the past quarter of a century; measuring GDP growth will tell us nothing about that. And it will certainly give us a wrong impression about the evolution of societal wellbeing. A striking fact is that in OECD countries the increase in income of 80 per cent of the population has been lower than the rate of growth of the overall economy (which is, obviously, an average) - and the more so the lower the decile considered. If we seek numbers that assess the impact of economic growth on society as a whole, surely we want to know what is happening to most people. GDP tells us nothing about that either.

Consider now the revolutions in the Arab world, especially Tunisia. Some economists construe political liberty as a luxury good, whose pursuit and maintenance leads to lower growth rates because it triggers a quest for redistribution. Setting aside whether such claims rest on sound theoretical or empirical foundations (at least in the case of Tunisia, the lack of democracy contributed to corruption, which had an enervating effect on growth), here too the concept used is misleading. GDP is not a measure of wellbeing: show that limiting political freedom leads to increased GDP and still (quite apart from the inherent fragility of such empirical exercises) it will be preposterous to conclude that countries should better postpone democratization until they can afford this luxury. It may well be that wellbeing increases more from an increase in political liberty than from an increase in GDP, especially given the way GDP is measured. And in any case, in debating the effect of political liberty on the evolution of GDP, we are missing an essential point: the risk taken by the people who fought and fight for freedom is testimony to the fact that freedom is a fundamental component of wellbeing.

These are just some examples of how flaws in the available metrics, and the absence of solid alternatives, may mislead us towards flawed policy conclusions. What we measure affects what we do. Reducing wellbeing in order to increase whatever imperfect measure of material wealth we like to use results in totally misguided policies.

\section{Metrics and policies}

Economists rely on statistical (econometric) data to make inferences about what are good policies. Those inferences are only as reliable as the data on which they are based. Some studies suggested that financial market or capital market liberalization contributed to higher economic growth, for instance, but it is now clear that such conclusions were flawed because: (1) GDP numbers were inflated by the bubbles that are often associated with such liberalizations; (2) unless an adequate time horizon is taken, the losses that follow crashes will not be taken into account - and these losses may more than offset the short-term gains arising from the bubbles to which liberalization often gives rise; (3) the distributive consequences of those policies are not taken into account, so that even if GDP goes up, it may still well be that most citizens are worse off; and (4) the costs to wellbeing from, for example, the insecurity that follows the volatility that typically accompanies such liberalization measures - are not taken into account. The empirical studies conducted to demonstrate the beneficial effect on growth and employment of financial market liberalization are vulnerable to the same limitations. There is an unfortunate correlation between some familiar policy recommendations and the weaknesses of the evidence supporting them.

Many advocates of unfettered markets see any intervention - whether through public policy or private institutions - as welfare-decreasing. They ignore extensive and well-documented 'market failures' that are especially widespread in labour and capital markets, however. Some institutions have been created to make up for failures in unemployment insurance markets, for instance. Some of these institutions can be thought of as reflecting some version of a democratic social contract. There are winners and losers to any structural reform, so such reform is unlikely to lead to a Pareto-improving outcome or even to one supported by a majority of the electorate. But, more importantly, the move towards greater labour flexibility could affect negatively at least two of the main objective determinants of wellbeing: the quality of jobs (the quest for a decent job) and economic security. Again, if we select the wrong indicators, we could draw policy recommendations whose implementation might actually reduce the wellbeing of the people. If our metrics do not capture the benefits of the greater security that unemployment insurance provides, the reform that is needed is not the abolition of unemployment insurance, but of the flawed metrics.

Another example arises in analyses of the effect of the size of government on growth. Because output in the public sector is typically measured by its inputs, there is an implicit assumption of no productivity growth (when in fact, in some cases, we know there is rapid productivity growth). Inevitably, such assumption taints crosscountry regressions to suggest that a larger public sector is associated with smaller rates of productivity growth. The result is not a deep empirical insight; it is simply a statistical artefact of measurement. Consider, for instance, 
what might happen if one were to privatize America's social security. We know that transaction costs for that system are one order of magnitude lower than for private annuity programmes. The system is extraordinarily efficient as it is, and surveys have also shown that it is very 'customer-responsive'. Privatization would result in higher profits for America's financial services industry, but lower benefits for America's retirees. The higher profits would likely be reflected in an increase in GDP but the wellbeing of Americans would be decreased, and the gains of the financial industry would be at the expense of retirees. Wellbeing, defined appropriately, would go down.

\section{Use and misuse of the concept of sustainability}

We can do better. The Commission on the Measurement of Economic Performance and Social Progress identified a number of reforms. Some would lead to a better GDP metric, so that even if GDP is not a measure of wellbeing it is a better measure of whatever it is that it is attempting to measure. We may want to measure, for instance, the levels of market activity - one of the original objectives of national income measurement. Sometimes confusion is engendered when a measure adapted to one purpose is used to highlight another. GDP is neither a measure of income nor a measure of wellbeing. What we want to measure is the key question.

Increasingly, there is a demand to go beyond measures of market activity to measures of wellbeing. Even before the crisis, there were worries about sustainability: our metrics did not tell us anything about whether what we were doing was sustainable. That is why some would want to shift focus to other metrics. Looking at the (real) income of the median individual, for example, would give us a better picture of what is happening to the typical individual in a given society than does GDP per capita. Before the crisis, many thought that the US was performing well; a look at the median income would have shown that incomes were actually stagnating or declining.

We care about the future. It is important for any society to form an assessment, no matter how imperfect, about whether its current consumption or wellbeing is sustainable, and whether this is coming at the expense of future generations. Our statistical systems should tell us whether or not what we are doing is sustainable economically, environmentally, politically or socially. Most of us believe that, at least in certain dimensions, what we are doing is not sustainable, but current statistics do not reflect this. Of course we can ascertain whether a society's wealth is increasing or decreasing (per capita), and if it is increasing then we may presume that such a society will be able to keep on doing in the future what it is doing today, i.e. whether it can sustain its per-capita income. But to get any useful information we need a comprehensive measure of wealth, and we need to be sure that the valuations are correct. A comprehensive measure obviously includes, for instance, measures of physical capital, human capital and natural capital (including the environment).

One of the problems encountered in the aftermath of the financial crisis is the misuse of the concept of sustainability. The lack of appropriate indicators of sustainability may lead us to an unsustainable path, while a partial measure may lead us to wrong policies, which would eventually jeopardize the long-term prospects of an economy. A case in point is Europe. Sharing a common currency in a global crisis, eurozone countries are currently looking for sustainability indicators in order to assess the financial sustainability of each member country. The problem is that European countries are focusing on a very partial view of sustainability, namely the sustainability of public debt, which leads them to impose austerity programmes on peripheral countries, i.e. procyclical policies. These will likely result in a much lower rate of growth, and eventually lead to financial unsustainability in both the public and private sectors.

Metrics are inevitably (if perhaps only partially) grounded in models. Many of the metrics upon which we focus are not seen as ends in themselves but are viewed as intermediate variables; they are of interest because they provide insight into those things we really care about. But the relationship between these intermediate variables and the things we really care about are often uncertain, and depends on the model. And of course there is a great deal of uncertainty about the right model. Prior to the crisis, many believed that all a country needed to do in order to maintain high and stable growth was to maintain low and stable inflation. After the crisis, a broad consensus has emerged that low and stable inflation was certainly not sufficient for economic stability. These policy conclusions were predicated on wrong models, which encouraged economists to focus on a single variable (inflation) as an indicator of the country's future prospects. We now know that there should have been more focus on indicators of financial stability.

\section{Assessing wellbeing}

While a focus on false measures might distort policy, a dialogue around what we as a society care about, and whether these concerns are adequately reflected in our statistics, could contribute not only to an enhanced understanding of the limitations of our models and measurements but to the formulation of better policies that are more reflective of the concerns and values of citizens.

The OECD Better Life Initiative, a study released in May 2011, shows the organization's openness to a dialogue 
with civil society. It allowed each citizen to build his own aggregate index of the quality of life. Eleven indicators were selected for the 34 OECD members as well as some emerging countries, according to the domains identified the report of the Commission on the Measurement of Economic Performance and Social Progress. People were asked to compute their own index by selecting the weight of each determinant of wellbeing, through an online interactive tool called Your Better Life Index.

Most of the determinants considered were objective (health, employment, education, housing conditions etc) but one was subjective, namely life satisfaction. This was assessed through surveys. The subjective determinants of wellbeing are obviously important: a long philosophical tradition views individuals as the best judges of their own situation. But they are subject to a kind of 'time inconsistency' problem: they may evaluate their circumstance (or even a particular event) in a different way at different points in time. While raising children, some people may describe the activity as painful yet, just a few years later, they may recall and describe this period as the most satisfactory of their lives.

How to interpret and use these different results in developing wellbeing metrics is a subject on which there is ongoing research. The value of such research is twofold: there is hope that it will lead to better metrics, and that the active engagement with civil society required to establish such metrics will itself facilitate policies directed at the improvement of societal wellbeing.

Surely, in the present circumstances, most countries need more growth; but growth of what? GDP? A better answer would be growth of wellbeing - that which matters to citizens. The shift requires most probably an enrichment of the instruments of public policies, and a much more selective approach to policies aimed at increasing GDP.

\section{Wellbeing and the business cycle}

This broader and redefined perspective on measurement is relevant not only for assessing the long-term progress of society, but also for understanding cyclical fluctuations such as the present one. Earlier we noted that before the crisis, GDP was exaggerated; but one can also argue that, during the crisis, the loss in wellbeing is being underestimated too. Various subjective measures of people's wellbeing agree that unemployment has a very adverse effect on people's quality of life. People who become unemployed report lower life evaluations, even after controlling for their lower income. The adverse effects seem to be intertemporally persistent. The unemployed also report higher prevalence of various negative effects (sadness, stress and pain) and lower levels of positive ones (joy). One may also suspect that the adverse effects of unemployment are felt even by those who are not themselves unemployed, especially in societies where unemployment is widespread. These subjective measures suggest that the costs of unemployment exceed the income loss suffered by the unemployed, reflecting the existence of nonpecuniary effects among them, and of fears and anxieties in the rest of society.

All of this suggests that economic fluctuations may have strong adverse effects on wellbeing. Again, the prevalent use of GDP as the intermediate indicator results in our not taking account of these effects explicitly - not only on the current level of wellbeing, but also on the 'stock' of human capital available in and to a given society. The economics of business cycles should then be rethought in the light of probable discrepancies between the fluctuation of output and that of wellbeing. It may well be better for governments to devise policies aimed at minimizing the rate of unemployment and its variation over the business cycle, rather than policies aimed at maximizing output growth as measured by GDP. Some of the instruments for implementing these two strategies may be the same - employment concerns are central to overall macroeconomic strategy - but surely the first strategy needs more complex and varied supplementary ones to smooth the evolution of unemployment. Moreover, in light of the preceding arguments, such a strategy will surely enhance wellbeing even if there were some adverse effects on growth, as measured by GDP.

The design of good policies cannot be grounded on the artificial separation between social and macroeconomic ones: if the wellbeing of the people is the ultimate end, employment, labour market analysis and income distribution must be central components of the macroeconomic analysis supporting stabilization policies.

\section{Author Information}

Jean-Paul Fitoussi is Professor Emeritus of the Institut d'Etudes Politiques de Paris (Sciences-Po), Paris and at LUISS Guido Carli University, Rome. He is also research director at OFCE, an institute dedicated to economic research and forecasting, and a member of the Centre for Capitalism and Society at Columbia University. Since 1997, he has been a member of the Economic Commission of the Nation.

Joseph E. Stiglitz is University Professor at Columbia and Co-chair of the University's Committee on Global Thought. He is also the cofounder and co-president of the Initiative for Policy Dialogue at Columbia. In 2001, he was awarded the Nobel Prize in Economics for his analyses of markets with asymmetric information. 